\title{
STUDIES ON RICE HULL ASH CEMENT
}

D. R. K. LOKULIYANA, M. G. M. U. ISMAIL

Minerals Tecbnology Section, Ceylon Institute of Scientific and Industrial Research, P. O. Box 787, Colombo 7, Sri Lanka.

and

R. P. GUNAWARDANE

Department of Chemistry, University of Peradeniya, Peradeniya, Sri Lanka.

(Date of receipt : 17 July 1986)

(Date of acceptance : 24 February 1987)

\begin{abstract}
Rice hull ash cement has been produced by grinding a mixture of rice hull ash and hydrated lime. The most suitable conditions for its production and the important properties of the product such as compressive strength, setting times and hydration have been investigated. The compressive strength of the cement is found to be in between the values for portland and masonry cements. Major hydration products have been identified as tobermorite gel, dicalcium silicate hydrate, xonolite and tobermorite type of calcium silicate hydrate. The binding property of cement can be-mainly attributed to the formation of tobermorite gel and dicalcium silicate hydrate. Observed variation of compressive strength of rice hull ash cement with composition, water content, curing time and fineness has been discussed.
\end{abstract}

\section{Introduction}

Rice hull is one of the major agricultural by-products in rice growing countries. Recently several Asian countries have found ${ }^{1}$ that rice hull ash obtained by burning rice hull possesses pozzolanic properties and hence a cheap pozzolanic type of hydraulic cement can be prepared by mixing with a calcareous material such as quick lime or hydrated lime. For the development of the quality of cement and to determine optimum conditions for production, it is essential to study the effect of lime/rice hull ash ratio, water/cement ratio, fineness, etc., on the strength and other physical properties of cement. It is also necessary to investigate the nature of hydration products.

This paper reports the results of investigation on the hydration process of rice hull ash cement and the nature of hydration products.

\section{Experimental}

Cement samples for this study were prepared by grinding a mixture of rice hull ash and hydrated lime in a ball mill. Since quick lime is highly reactive and difficult to handle hydrated lime has been used in the present study. 
The rice hull ash was obtained by burning two different varieties of rice hull BG 11-11 and BG 34-8 under different laboratory conditions. Physical properties such as compressive strength, standard consistency, setting times, fineness, specific gravity, bulk density and loss on ignition have been investigated. The standard consistency and setting times were determined by using Vicat apparatus, compressive strength and fineness by using universal compression testing machine and Blaine air permeability apparatus, model EL 38-100, respectively. These determinations have been carried out according to the methods described in the British Standard. ${ }^{2}$

Cement samples were hydrated by mixing $1 \mathrm{~g}$ of cement with $0.66 \mathrm{ml}$ of distilled water in a petri dish for $24 \mathrm{~h} ., 7,28,60$ and 90 days. Area of the paste was made to about one square inch and kept at room temperature $\left(25^{\circ} \mathrm{C}\right)$ and under atmospheric pressure. A mixture of rice hull ash $(0.73 \mathrm{~g})$ and hydrated lime $(0.27 \mathrm{~g})$ was hydrated with the same amount of water and kept under the same conditions. The hydrated samples were examined by differential thermal analysis (DTA) and X-ray powder diffraction. Instruments used for this study were MOM, Q-Derivatograph and JDX-8SD with $\mathrm{K}_{\propto}$ radiation, respectively.

\section{Results and Discussion}

\subsection{Preliminary Studies on Cement}

Figure 1 shows the variation of compressive strength of cement with rice hull ash to hydrated lime ratio. The most suitable ratio of rice hull ash and hydrated lime for production of cement was found to be 8:3. The compressive strength of cement increases with increase of water/cement ratio upto 0.6 and decreases, as shown in Figure 2. This indicates that the water requirement of cement is high when compared with ordinary portland cement. The relationship between development of strength of cement and duration of curing of mortar cubes is given in Figure 3.

It has been found that the compressive strength increases rapidly upto 7 days and then increases very slowly with time. This indicates that the concentration of hydrated compounds which are responsible for binding property increases rapidly upto 7 days. Figure 4 shows the relationship between the compressive strength of cement and grinding time. It was found that the strength increases with increase of grinding time. This indicates that the compressive strength of this kind of pozzolana cement is proportional to the fineness of cement. 


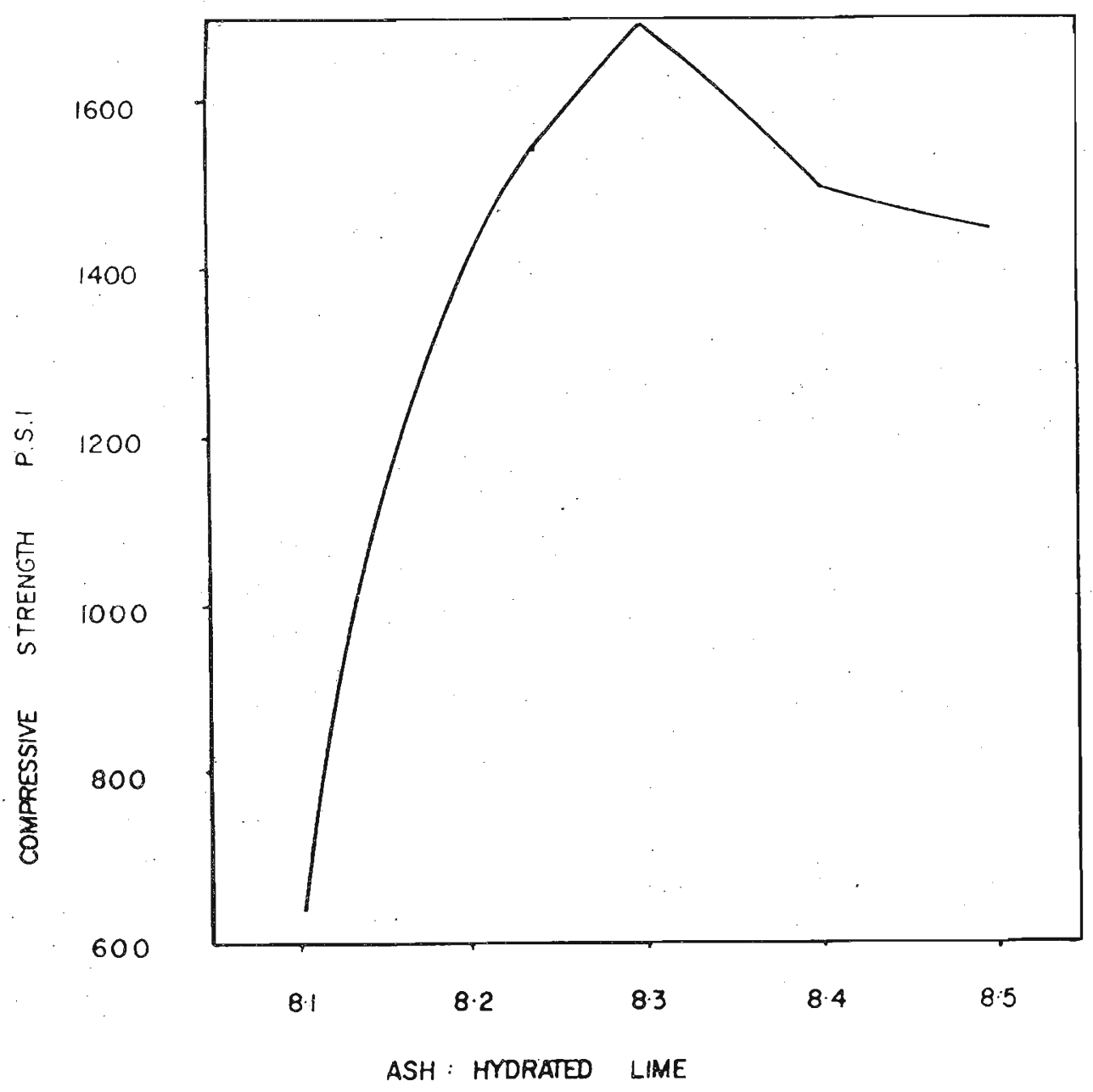

Figure 1. Effect of composition of mixture on compressive strength 


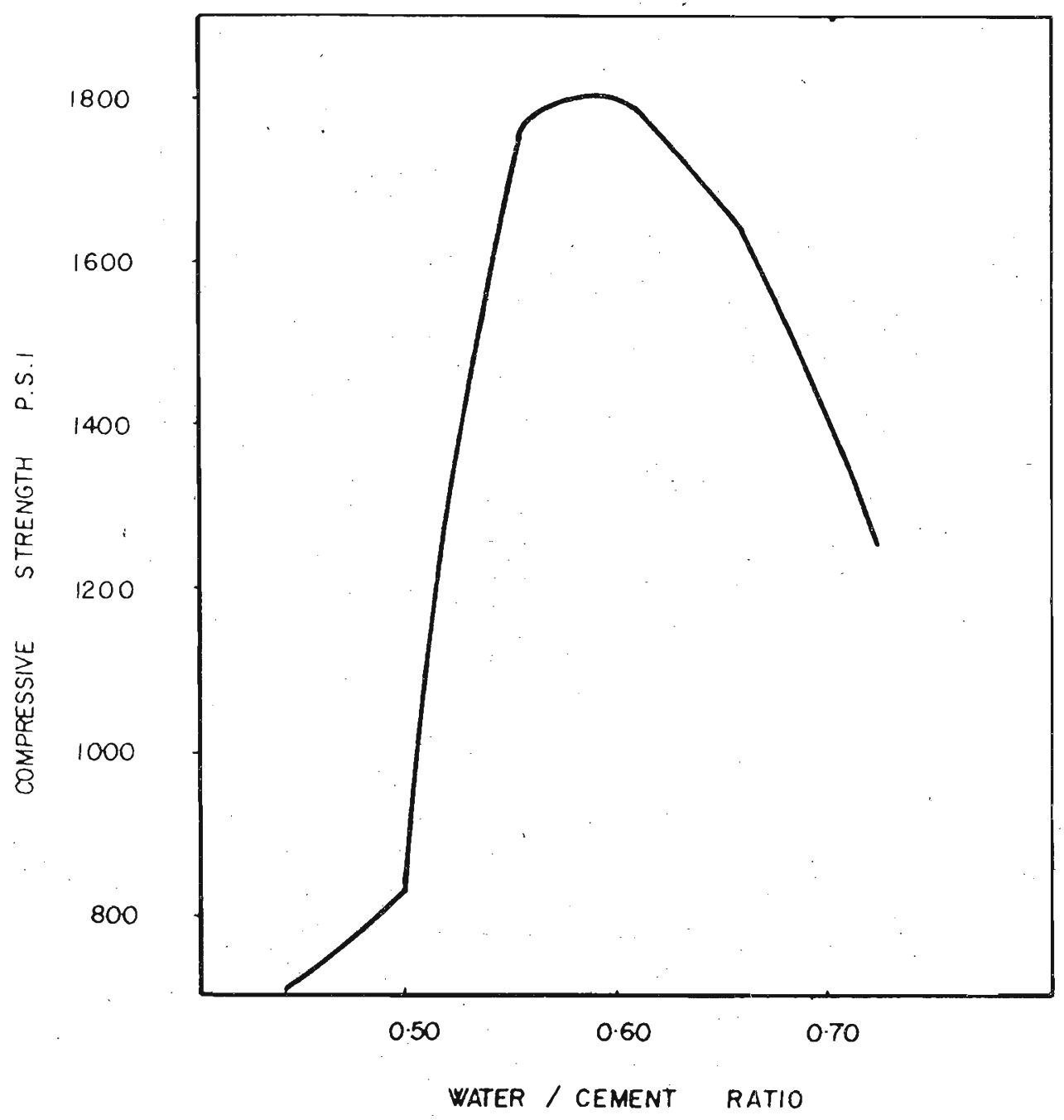

Figure 2. Effect of water/cement ratio on compressive strength 


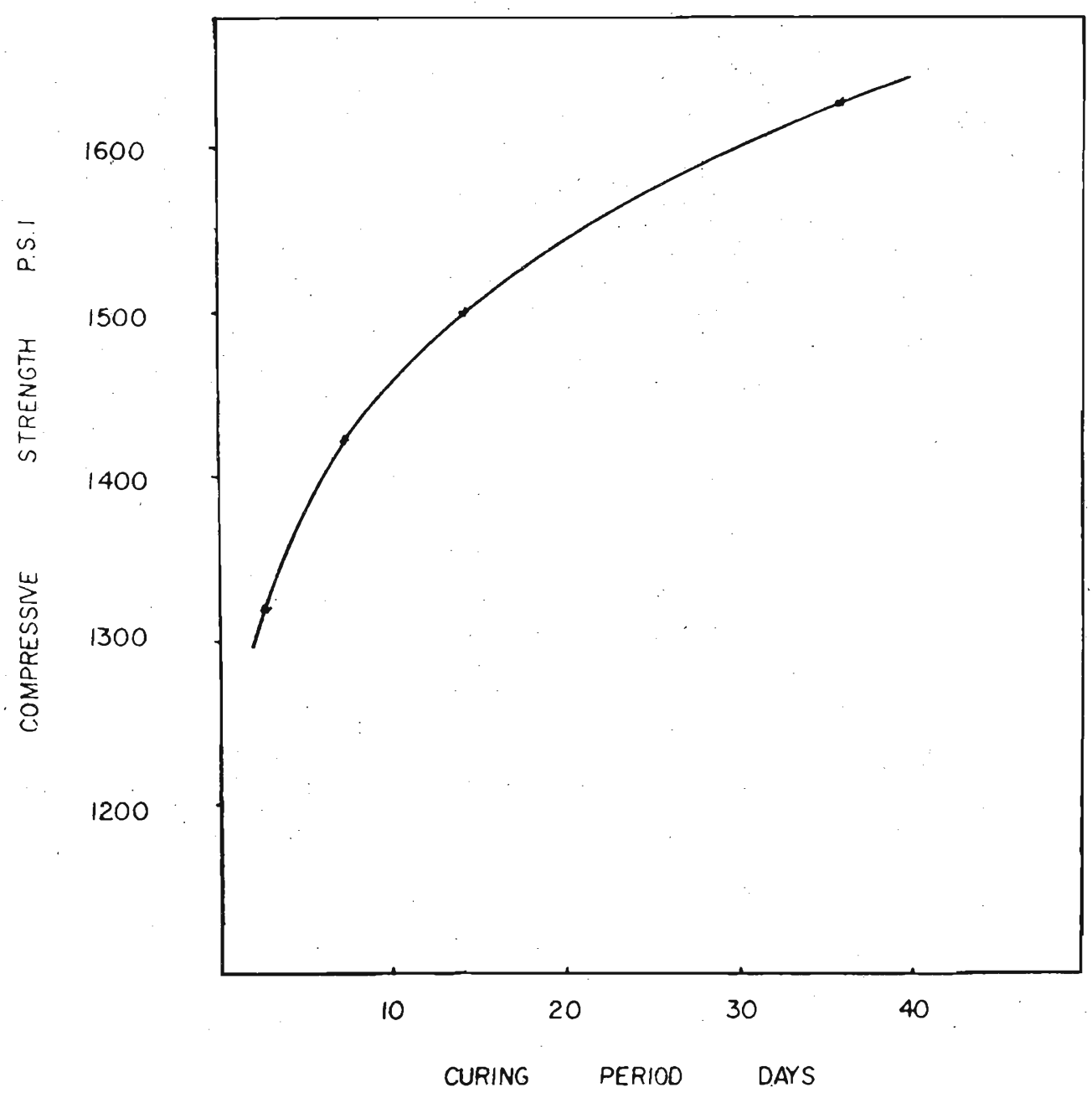

Figure 3. Effect of curing period on compressive strength 


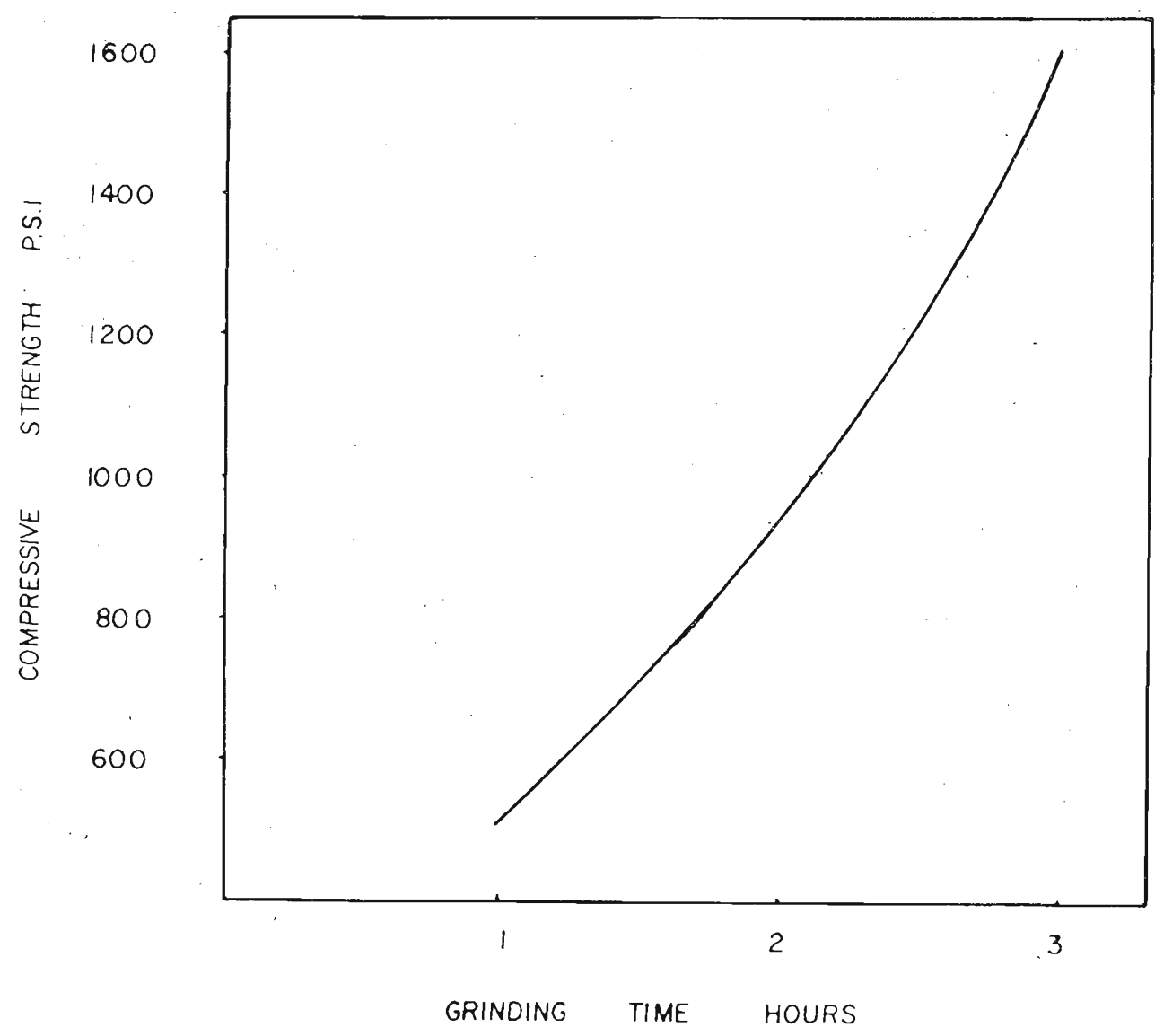

Figure 4. Effect of grinding time on compressive strength 


\subsection{Physical Properties of Cement}

Table 1. Physical properties of rice hull ash cement and portland cement

\begin{tabular}{lll}
\hline Physical Property & $\begin{array}{l}\text { R.H.A. Cement } \\
\text { (Present study) }\end{array}$ & Portland Cement \\
\hline $\begin{array}{l}\text { Compressive } \\
\text { strength at } 7 \text { days } \\
\text { p.s.i }\end{array}$ & 1922 & 4714 \\
\hline $\begin{array}{l}\text { Setting times } \\
\text { minutes }\end{array}$ & $\begin{array}{l}\text { initial }-50 \\
\text { final }-140\end{array}$ & $\begin{array}{l}\text { initial }- \text { not less than } 45 \\
\text { final }- \text { not more than } 600\end{array}$ \\
\hline
\end{tabular}

Standard Consistency

$\%$ by weight

70.67

40.00

\begin{tabular}{lll}
\hline $\begin{array}{l}\text { Loss on ignition } \\
\% \text { by weight }\end{array}$ & 12.59 & $\begin{array}{l}\text { shall not exceed } \\
4\end{array}$ \\
\hline Specific gravity & 2.43 & $3.12^{*}$ \\
\hline Bulk density $\mathrm{g} / \mathrm{ml}$ & 0.61 & $1.51^{*}$ \\
\hline Fineness $\mathrm{cm}^{2} / \mathrm{g}$ & 6986 & 4000 \\
\hline
\end{tabular}

Note: These values for portland cement have also been experimentally determined in the present study.

Table 1 gives a comparison of some of the important physical properties of rice hull ash cement and portland cement. ${ }^{2}$ Compressive strength of cement is in between masonry and ordinary portland cement. Setting times and standard consistency are almost under the specification limits of ordinary portland cement. Specific gravity and bulk density are very low when compared with portland cement. This is mainly due to the presence of a large amount of organic matter in rice hull ash and also due to the presence of amorphous silica and hydrated lime as unreacted forms in cement. High loss on ignition is due to the oxidation of organic matter in rice hull ash and the decomposition of hydrated lime.

\subsection{Hydration Studies}

DTA and X-ray diffraction pattern of hydrated samples are shown in Figures 


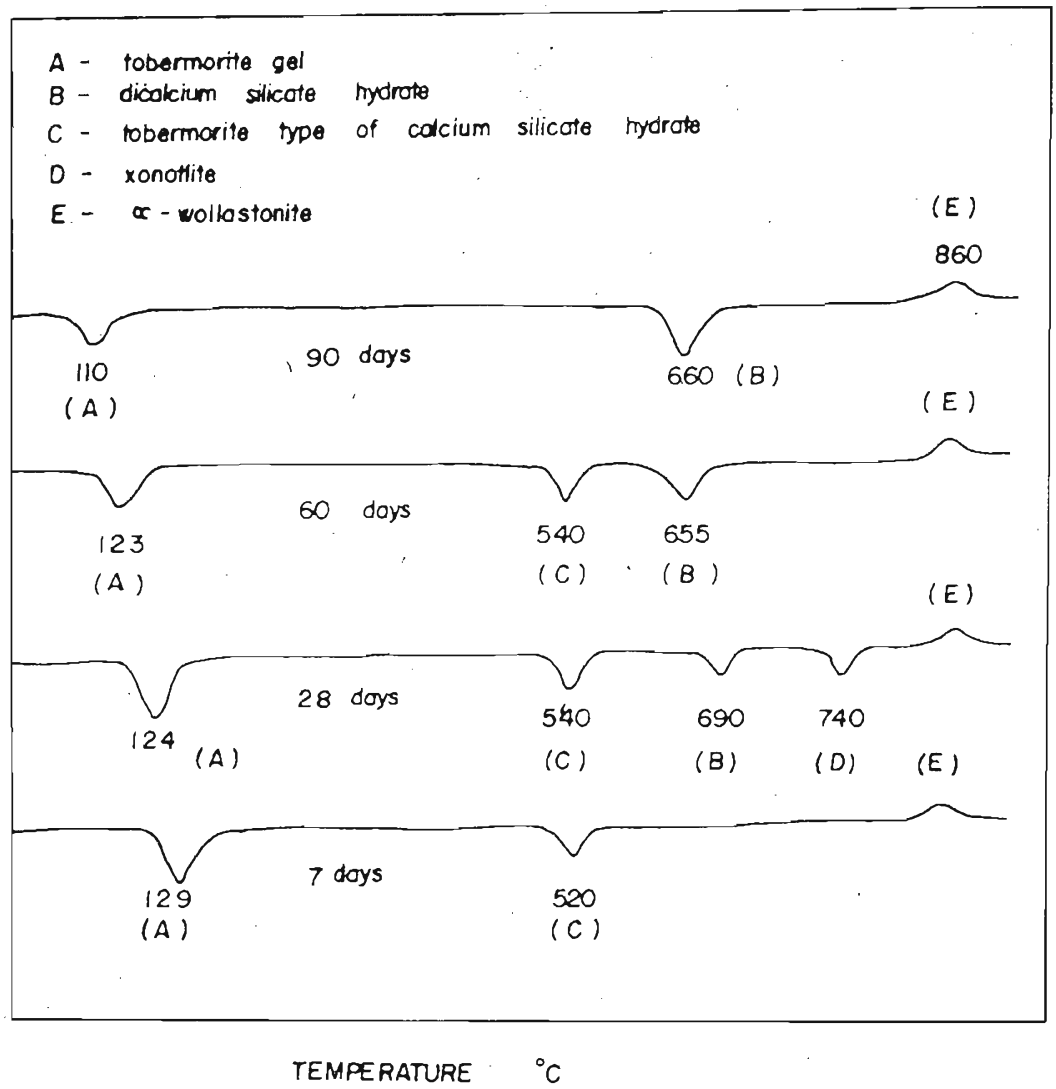

Figure 5. DTA of hydrated cement 


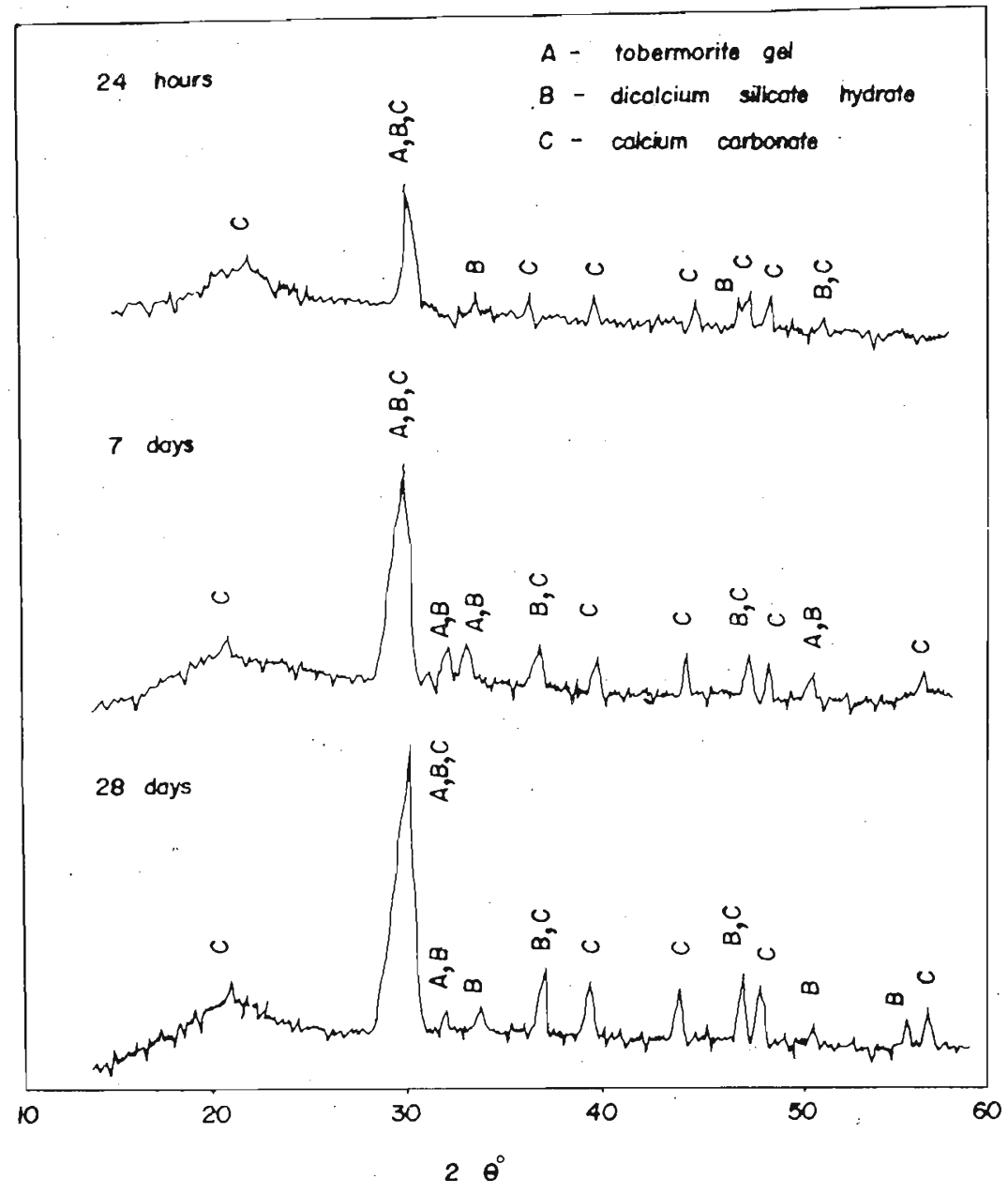

Figure 6. XRD pattern of hydrated cement " 
5 and 6. Hydrated compounds such as tobermorite gel, dicalcium silicate hydrate, tobermorite type of calcium silicate hydrate and xonolite have been detected. DTA also showed an exothermic reaction at $860^{\circ} \mathrm{C}$ due to formation of $\alpha$-wollastonite from $\mathrm{CaO}$ and amorphous silica.

This kind of dehydration reactions were observed by thermal treatment of artificial and natural minerals. ${ }^{3,4}$ It is significant that the dehydration temperature of tobermorite gel decreases with increase of duration of the hydration period. This is because the dehydration temperature of tobermorite gel depends on the proportion of free water and water of tobermorite gel.

These results indicate that the concentration of tobermorite gel increases upto 7 days and then decreases with increase of hydration period. X-ray diffraction pattern of tobermorite gel consists of a few broad peaks which were observed at $3.06,2.86$ and $1.82 \AA$.

It was found that the X-ray diffraction pattern of dicalcium silicate hydrate shows a series of sharp peaks and their intensity increases with increase of duration of hydration period. This shows that the concentration of dicalcium silicate hydrate increases with increase of hydration time. The variation of concentration of tobermorite gel, concentration of dicalcium silicate hydrate and compressive strength with time is represented in Figure 7.

The rapid increase of compressive strength in the earlier period of curing is due to the sudden increase of tobermorite gel content. Then the slow increase of strength is due to the increase of concentration of dicalcium silicate hydrate. Therefore, this clearly indicates that there is a significant effect of variation of concentration of tobermorite gel on the strength. These results suggest that the tobermorite gel formed in the earlier period is unstable and therefore, it begins to convert into dicalcium silicate hydrate. The instability of tobermorite gel is most probably due to its less $\mathrm{CaO} / \mathrm{SiO}_{2}$ ratio and this is less than the value observed in portland cement paste. The observed ratio is less than two and it increases upto two by releasing amorphous silica in to the medium.

The possible reaction sequence can be given as follows.

\begin{tabular}{|c|c|}
\hline$x \mathrm{CaO} \cdot \mathrm{y} \mathrm{SiO}_{2} \cdot \mathrm{H}_{2} \mathrm{O} \rightarrow$ & $2 \mathrm{CaO} \cdot \mathrm{SiO}_{2} \cdot \mathrm{H}_{2} \mathrm{O}+\mathrm{z} \mathrm{SiO}_{2}$ \\
\hline tobermorite gel & $\begin{array}{l}\text { dicalcium } \\
\text { silicate } \\
\text { hydrate }\end{array}$ \\
\hline
\end{tabular}

$(\mathrm{x} / \mathrm{y}<2)$ 


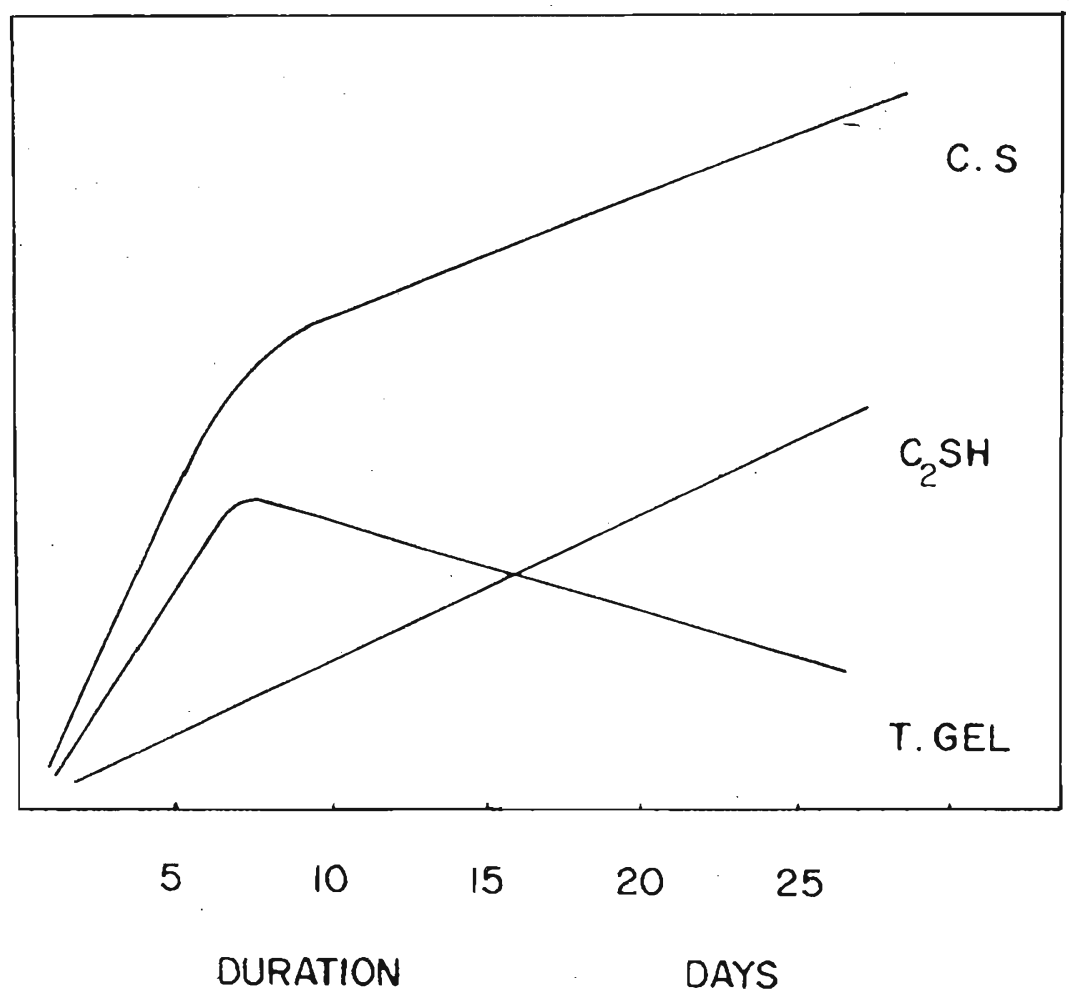

Figure 7. Variation of tobcrmorite gel, dicalcium silicate hydrate and compressive strength with duration 
The hydrated mixture of rice hull ash and hydrated lime after 28 days showed the presence of organic matter, $\mathrm{CaCO}_{3}$, amorphous silica, tobermorite type of calcium silicate hydrate and xonolite. This indicates that the fineness of the rice hull ash particles is not sufficient to produce tobermorite gel.

\subsection{Studies on Unhydrated Cement}

It has been found that the two major constituents of cement, amorphous silica and $\mathrm{Ca}(\mathrm{OH})_{2}$ are present as free (unreacted) forms. Differential thermal analysis showed the formation of dicalcium silicate hydrate at $480^{\circ} \mathrm{C}$ as a result of reaction between amorphous silica and $\mathrm{Ca}(\mathrm{OH})_{2}$. It was found that the reaction depends on the activity of silica. The formation of $\alpha$-wollastonite was observed at $860^{\circ} \mathrm{C}$ and this reaction depends on the activity and particle size of the silica source.

\section{Conclusions}

The two main constituents of rice hull ash cement, amorphous silica and $\mathrm{Ca}(\mathrm{OH})_{2}$ are present as free (unreacted) forms. During hydration these two react to form hydrated compounds. Bulk of the hydrated cement sample consists of large amounts of amorphous silica and $\mathrm{CaCO}_{3}$. On hydration, two main compounds, tobermorite gel and dicalcium silicate hydrate are formed. The binding property of cement is mainly attributed to the formation of these two compounds. In addition to these two, other calcium silicate hydrates such as tobermorite and xonolite are also formed in very small quantities. However, these two compounds were not detected by XRD analysis because of their low concentrations.

\section{Acknowledgements}

The authors wish to thank the Natural Resources, Energy and Science Authority for awarding a research grant to carry out this work and also to the staff of Minerals Technology Section of the Ceylon Institute of Scientific and Industrial Research for their assistance.

\section{References}

1. Rice husk ash cement : Proceedings of a joint workshop, (1979); Bangalore 560052, India : Regional Centre for Technology Transfer.

2. British Standard BS 12,(1978), Specification for ordinary and rapid hardening Portland Cement, British Standard Institution.

3. HELlER, L., TAYLOR, H. F. W., (1951), Hydrated calcium silicates, Part II, J. Cbem. Soc., 2397-2401.

4. HELLER, L., TAYLOR, H. F. W., (1956), Crystallographic data for the calcium silicates, Her Majesty's Stationary Office, London. 